Check for updates

Cite this: Chem. Sci., 2018, 9, 2918

\title{
A trichromatic MOF composite for multidimensional ratiometric luminescent sensing $†$
}

\author{
He Zhao, (D) a Jun Ni, (D) a Jian-Jun Zhang, (D)*ad Shu-Qin Liu, (D) a Ying-Ji Sun, (D) ${ }^{a}$ \\ Huajun Zhou, (D)*b Yan-Qin Li (D) and Chun-Ying Duan (DD*c
}

Low-cost, high-performance luminescent probes with wide application potential have been actively pursued. Conventional luminescent probes, which rely on single or dual emissions responsive to analyte molecules, demonstrate limited sensitivity and selectivity because the single emissions can be easily affected by many non-analyte factors, while the dual emissions can only offer single-ratiometric luminescent sensing. Here we report a white-light-emitting trichromatic MOF composite (W2) as the first multidimensional ratiometric luminescent probe. It is facilely synthesized by simultaneously incorporating red- and green-emitting iridium and ruthenium complex cations as encapsulated luminescent modules (ELMs) into a porous blue-emitting MOF via ion exchange. Specific volatile organic solvents (VOSs) can cause VOS-dependent changes to the MOF-to-ELM energy transfer efficiencies in W2, while nitroaromatic (NAC) vapors intriguingly and unprecedentedly quench the three emissions at different rates, both of which enable visible luminescent sensing. Each VOS can be correlated to a unique combination of the two MOF-to-ELM ratios of emission-peak heights, enabling a two-dimensional (2D) code recognition. Furthermore, the time-dependent evolution of the two ratios upon exposure to selective NAC vapors can be mapped out, achieving the first 3D code recognition. Both the synthetic and sensing strategies can be further implemented to develop low-cost and effective luminescent probes.

Received 3rd January 2018

Accepted 10th February 2018

DOI: $10.1039 / \mathrm{c} 8 \mathrm{sc00021b}$

rsc.li/chemical-science both the components and their connectivity modes, as well as versatile post-synthetic modifications, can equip MOF-based materials with desired structures, properties, and functionalities. $^{6,7}$ For example, their finely regulated porosities can concentrate analyte molecules to amplify the sensing signals and thus increase sensitivity. ${ }^{8}$ They can also provide tailored porosities and environments for analyte molecules to boost selectivity, ${ }^{9}$ and their rich excited-state energy levels can help generate versatile luminescence signals. ${ }^{\mathbf{1 0}}$ All these features make MOF-based materials more advantageous than conventional small molecules in luminescent sensing.

Up to now, many luminescent MOFs have been used to detect different analytes. ${ }^{4,5}$ However, among them, the vast majority output the luminescence intensity evolution of single emissions as their signals when analyte molecules interact with MOFs to turn their emissions on or off. Such monochromatic luminescence signals are not accurate because many nonanalyte factors such as unstable instrumental parameters and background luminescence can alter the absolute solid-state luminescence intensities. ${ }^{11}$ Furthermore, such signals are not easily detected by the naked eye. In contrast, sensing based on the luminescence energy changes and visible emission color changes is more sensitive and can be useful in on-site detection. However, such probes are extremely rare because they are generally based on strong host-analyte interactions and thus require elaborate designs for both ligands and frameworks. ${ }^{\mathbf{1 2}}$ 
Recently an alternative method has involved the incorporation of dyes or $\mathrm{Ln}^{3+}$ ions as encapsulated luminescent modules (ELMs) into porous luminescent MOFs to afford dichromatic composites. ${ }^{13-15}$ Upon exposure to VOSs, the intensity of the two emissions from both the MOF ( $\left.I_{\mathrm{MOF}}\right)$ and ELM $\left(I_{\mathrm{ELM}}\right)$ varies, sometimes accompanied by visible emission color changes; furthermore, a dimensionless and VOS-dependent factor, i.e., $I_{\mathrm{MOF}} / I_{\mathrm{ELM}}$, is developed to sense VOSs (Scheme 1a). Such onedimensional (1D) single-ratiometric detection is selfreferencing, more reliable and more sensitive than those based on monochromatic MOFs. However, the colors before and during sensing are merely intermediates of the two original colours, resulting in limited color changes and sensing capabilities (Scheme 1b). Therefore, high-quality MOF-based luminescent probes are still being actively sought.

Herein we present a novel white-light-emitting (WLE) MOF composite (W2, CIE coordinate: $(0.33,0.34)$ ) using its three tunable red-green-blue emissions for multidimensional ratiometric luminescent sensing. The composite is facilely obtained

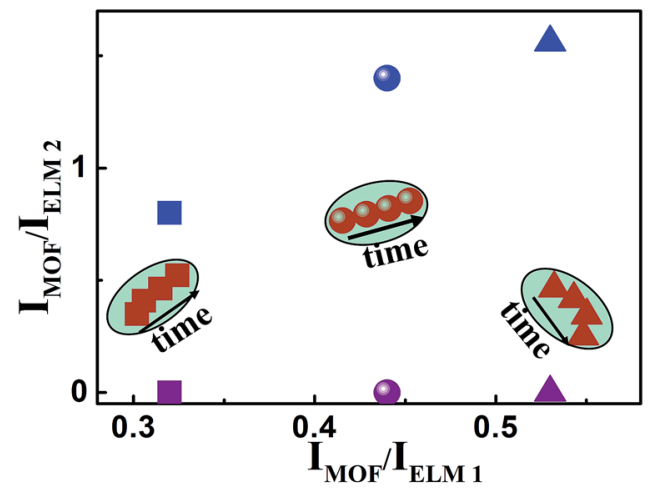

(a)

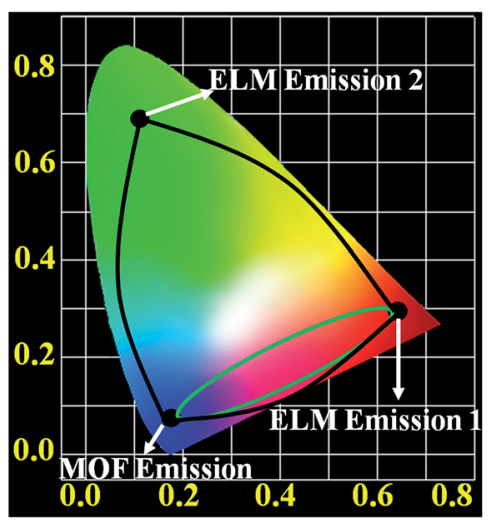

(b)

Scheme 1 (a) A comparison of 1D (purple), 2D (blue) and 3D (red) code recognition of analytes based on ratiometric luminescent sensing. Different shapes of data points represent different analytes; (b) schematic diagrams illustrating a second difference between $1 D$ and 2D ratiometric luminescent sensing before and during the sensing: the accessible luminescence colours are limited to the intermediates of two emissions as outlined in the green elliptical region in 1D but can reach the whole visible spectrum in 2D sensing. from the simultaneous incorporation of specific amounts of green- and red-emitting complex cations, namely [ $\operatorname{Ir}\left(\mathrm{CF}_{3}-\mathrm{ppy}-\right.$ $\left.\left.\mathrm{F}_{2}\right)_{2}(\mathrm{bpy})\right]^{+}$and $\left[\mathrm{Ru}(\mathrm{bpy})_{3}\right]^{2+}$, into a new blue-emitting MOF $\left(\mathrm{Me}_{2} \mathrm{NH}_{2}\right) \quad\left[\mathrm{Zn}_{2}(\mathrm{~L}) \quad\left(\mathrm{H}_{2} \mathrm{O}\right)\right] \cdot 4 \mathrm{DMA} \quad(\mathbf{1}) \quad\left(\mathrm{H}_{5} \mathrm{~L}=2,5-\right.$ (6-(3-carboxyphenylamino)-1,3,5-triazine-2,4-diyl-diimino) diterephthalic acid); DMA $=N, N$-dimethylacetamide) (note: hereafter complex cations $\left[\operatorname{Ir}\left(\mathrm{CF}_{3}-\mathrm{ppy}-\mathrm{F}_{2}\right)_{2}(\mathrm{bpy})\right]^{+}$and $\left[\mathrm{Ru}(\mathrm{bpy})_{3}\right]^{2+}$ are abbreviated as $[\mathrm{Ir}]^{+}$and $\left.[\mathrm{Ru}]^{2+}\right)$. The composition of W2 can be formulated as $1 \supset\left(0.28 \mathrm{wt} \%[\mathrm{Ir}]^{+}+0.45 \mathrm{wt} \%\right.$ $\left.[\mathrm{Ru}]^{2+}\right)$. The anionic framework in $\mathbf{1}$ with large cages and channels enables the inclusion of the complex cations while the WLE is achieved by tuning their mole ratios and then emissionintensity ratios. The two MOF-to-ELM ratios of their emissionpeak heights, i.e., $I_{\mathrm{MOF}} / I_{\mathrm{ELM} 1}$ and $I_{\mathrm{MOF}} / I_{\mathrm{ELM}}$ 2, (Scheme 1a) are acquired to achieve two-dimensional (2D) ratiometric luminescent sensing of VOSs and NACs. Such 2D ratiometric luminescent probes are advantageous over the above-mentioned 1D counterparts in three ways. First, the two ratios can be simultaneously changed by an analyte so that the resultant colors can be achieved within the whole visible spectrum and be drastically different from the original white color, enabling the changes to be easily detected by the naked eye (Scheme 1b). Such sensing mechanisms make strong host-analyte interactions unnecessary for effective luminescent sensing and open up great opportunities to develop more capable luminescent probes. Second, a unique $2 \mathrm{D}$ code recognition of analytes can be established because each analyte has a characteristic combination of the two ratios. Third, such an approach can be further implemented to record the time-dependent evolution of the two ratios for specific analytes (data points clustered in a region for each analyte are shown in Scheme 1a), adding time as a new dimension and enabling 3D ratiometric luminescent sensing. Obviously, such self-referencing methods double or triple the output information and thus significantly enhance the detection selectivity and sensitivity. In comparison to sensing with a set of three "physically mixed" probes, here the energy transfer between the framework and ELMs can be more effectively tuned by analytes to amplify the changes of the two ratios, leading to much higher sensitivity.

Indeed, WLE W2 demonstrates the expected sensing results. Upon exposure to certain VOSs and NAC vapours, W2 undergoes sharp luminescence color changes due to the remarkable change of the two ratios (i.e., $I_{\mathrm{MOF}} / I_{[\mathrm{Ir}]}{ }^{+}$and $I_{\mathrm{MOF}} /$ $\left.I_{[\mathrm{Ru}]}^{2+}\right)$. Such ratios provide each VOS or NAC with a unique data point, enabling 2D orthogonal identification. Furthermore, this work has allowed the following achievements that have never been reported before to the best of our knowledge. First, NAC vapors intriguingly quench the three emissions in W2 at different rates; remarkably, $m$-dinitrobenzene ( $m$-DNB) vapor is quickly detected (in $1 \mathrm{~min}$ ) based on dramatic changes of luminescence colors. Second, here the WLE composite is used for ratiometric luminescent sensing of VOSs and NACs. Third, the time-dependent evolution of two ratios upon exposure to $\mathrm{NB}, o$-DNB, and $m$-DNB vapors is mapped out, enabling an unprecedented $3 \mathrm{D}$ code differentiation of those similar structures. 


\section{Results and discussion}

\section{Structure and characterization of 1}

Colourless crystals of $\mathbf{1}$ were obtained from a solvothermal reaction of $\mathrm{H}_{5} \mathrm{~L}$ and $\mathrm{Zn}\left(\mathrm{NO}_{3}\right)_{2} \cdot 6 \mathrm{H}_{2} \mathrm{O}$ in DMA/ $\mathrm{H}_{2} \mathrm{O}$. Single-crystal $\mathrm{X}$-ray diffraction analysis revealed that 1 has a $3 \mathrm{D}$ framework based on 3-connected dinuclear quasi-paddlewheel $\left\{\mathrm{Zn}_{2}(\mathrm{COO})_{5}\right\}$ (MBBs) and $\mathrm{L}^{5-}$ ligands. The two nodes are connected in a $1: 1$ ratio to build a $3 \mathrm{D}$ anionic $b c u-f$ network that has a Schläfli symbol of $\left\{8 ; 10^{2}\right\}$ according to TOPOS calculation $^{\mathbf{1 6}}$ (Fig. S2 $\dagger$ ). From another point of view, the framework is built of bowl-shaped $\left\{\mathrm{Zn}_{16} \mathrm{~L}_{4}\right\}$ SBBs (Fig. 1A and B), each of which is composed of eight $\left\{\mathrm{Zn}_{2}(\mathrm{COO})_{5}\right\}$ MBBs and four $\mathrm{L}^{5-}$ ligands, and is $11.4 \times 20.0 \times 11.73 \AA^{3}$ in dimension. Topologically each SBB is eight-connected, and the structure is a mononodal $b c u$ network with its Schläfli symbol being $\left\{4^{24} ; 6^{4}\right\}$ (Fig. S3 $\dagger$ ). The SBBs are packed to afford 1D cross-shaped channels ( $\sim 16 \AA$ in length) along the $c$ direction. The solvent accessible volume of the guest-free form of $\mathbf{1}$ is calculated using PLATON $^{17}$ to be about $68.9 \%$ of the total volume.

Powder X-ray diffraction (PXRD) analysis confirms the purity and crystallinity of the bulk sample (Fig. S6†). Thermogravimetric analysis (TGA) (Fig. S8†) reveals that 1 loses all coordinated water and free DMA solvent molecules before
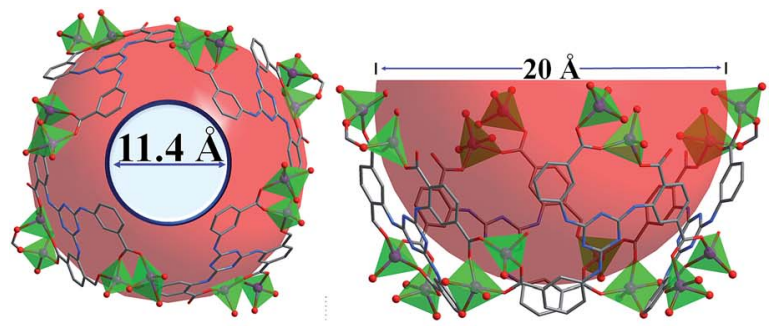

(a)

(b)

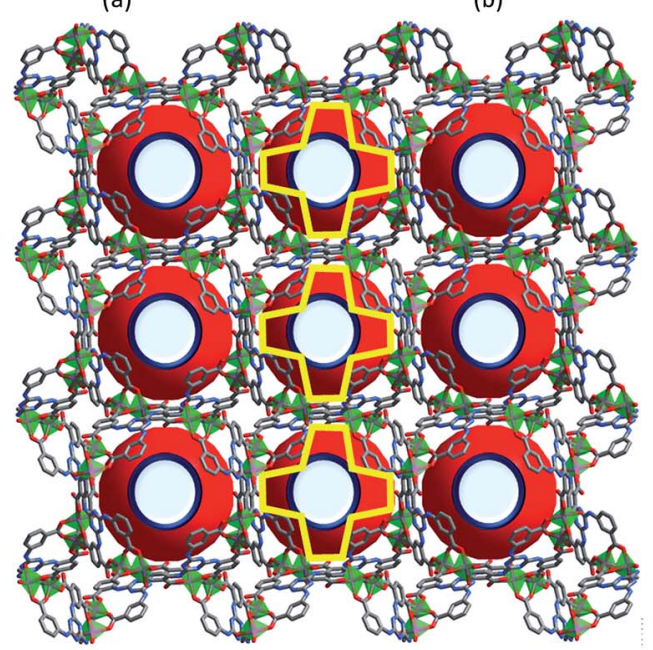

(c)

Fig. 1 The structure of compound 1. Top (a) and side (b) views of the bowl-shaped $\left\{Z_{16} \mathrm{~L}_{4}\right\}$ SBB; (c) the framework viewed along the $c$ axis; the yellow crosses outline the shapes of the channels. reaching $200{ }^{\circ} \mathrm{C}$ (exp. 34.55\%; calc. 32.93\%). The solid-state luminescence spectra of $\mathrm{H}_{5} \mathrm{~L}$ and $1\left(\lambda_{\mathrm{ex}}=365 \mathrm{~nm}\right)$ collected at room temperature (Fig. S9†) show the intense emissions of $\mathrm{H}_{5} \mathrm{~L}$ and 1 peaked at $470 \mathrm{~nm}$ and $416 \mathrm{~nm}$, respectively. The CIE coordinate for 1's blue emission is $(0.16,0.07)$ which is close to that of the saturated blue emitter, $(0.14,0.08)$.

\section{Encapsulation of the ELMs and fabrication of the WLE composite}

Complex spherical cations $[\mathrm{Ir}]^{+}$and $[\mathrm{Ru}]^{2+}$ (structures are shown in Fig. $55 \dagger$ ) were chosen as ELMs for two main reasons. First, they are $\sim 14$ and $\sim 12 \AA$ in diameter, respectively, and both are smaller than the channels in $\mathbf{1}$. Second, upon excitation at $365 \mathrm{~nm}$, their solid-state green and red emissions (CIE coordinates: $(0.28,0.52)$ and $(0.55,0.44)$, respectively) are much stronger than the blue emission of $\mathbf{1}$. Therefore, relatively small amounts $\left(0.28 \mathrm{wt} \%\right.$ and $0.45 \mathrm{wt} \%$ for $[\mathrm{Ir}]^{+}$and $[\mathrm{Ru}]^{2+}$, respectively, in W2) of such expensive cations can complement 1 to achieve WLE and leave enough vacant space for further sensing, while saving costs. A similar encapsulation strategy has been recently used to prepare MOF-based composites with luminescent dyes as ELMs for WLE applications. ${ }^{18}$ Compared to organic dyes, noble metal complex cations are better ELMs for ratiometric luminescent sensing due to their higher quantum yields of luminescence, longer lifetime, better photostability and higher sensitivity to external stimuli. ${ }^{19}$

We first found that each complex cation could be individually exchanged into 1 to afford $1 \supset[\mathrm{Ir}]^{+}$or $\mathbf{1} \supset[\mathrm{Ru}]^{2+}$ when 1 was soaked in a methanol solution of $\left[\operatorname{Ir}\left(\mathrm{CF}_{3}-\mathrm{ppy}-\mathrm{F}_{2}\right)_{2}(\mathrm{bpy})\right]\left(\mathrm{PF}_{6}\right)$ or $\left[\mathrm{Ru}(\mathrm{bpy})_{3}\right]\left(\mathrm{PF}_{6}\right)$ for $24 \mathrm{~h}$. The amount of $[\mathrm{Ir}]^{+}$or $[\mathrm{Ru}]^{2+}$ included was controlled by varying the solution concentrations, and was accurately determined using luminescence measurements of the filtrates (Fig. S12 and S13 $\dagger$ ). No cations leaked out from the framework when the cation-exchanged phases were soaked in methanol for an additional $24 \mathrm{~h}$ (Fig. S14 $\dagger$ ), indicating the stabilization of these ELMs, which is possibly due to electrostatic interactions. The PXRD analysis reveals that the resultant phases maintain the original framework (Fig. S7†) while the laser confocal scanning analysis of a single crystal to different depths reveals that these ELMs are uniformly dispersed throughout 1 (Fig. S15 and S16†). Compared to those in their pure phases, the emissions of $\mathbf{1}$ and of the ELMs in the composites show obvious red and blue shifts, respectively (Fig. S17 and S18†), due to the 'rigidochromic effect' ${ }^{18}$ As the concentration of these ELMs increases, the blue emissions from the framework gradually decrease, and the emissions from the ELMs increase along with the blue shifts, both indicating excitation energy transfers from the framework to the ELMs. The efficient resonance energy transfers are also supported by the spectral overlap between the absorption of $\left[\operatorname{Ir}\left(\mathrm{CF}_{3}-\mathrm{ppy}\right.\right.$ $\left.\left.\mathrm{F}_{2}\right)_{2}(\mathrm{bpy})\right] \mathrm{PF}_{6} /\left[\mathrm{Ru}(\mathrm{bpy})_{3}\right]\left(\mathrm{PF}_{6}\right)_{2}$ and the emission from $\mathbf{1}$ (Fig. S19†).

We further found that both cations could be simultaneously included into $\mathbf{1}$ when $\mathbf{1}$ was soaked in a solution containing both cations (Fig. 2). Different WLE composites with different amounts of ELMs can be obtained by tuning their 


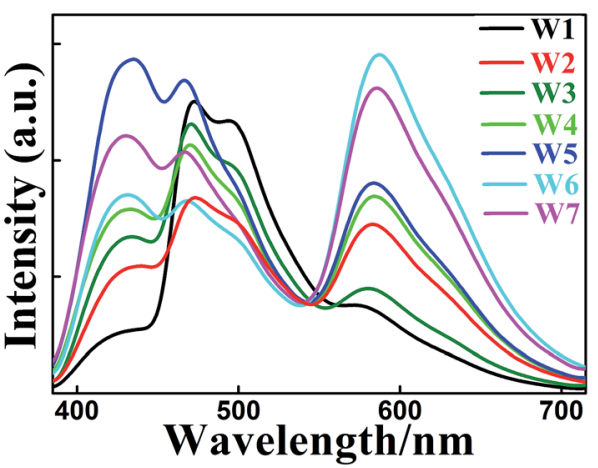

(a)

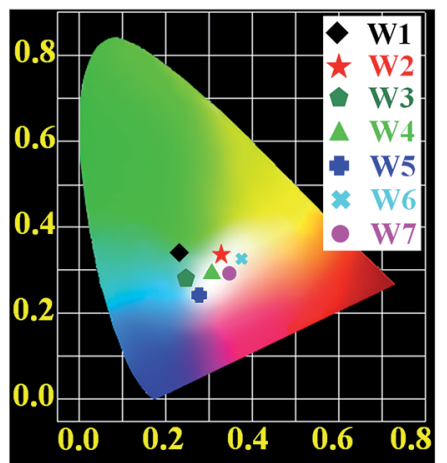

(b)

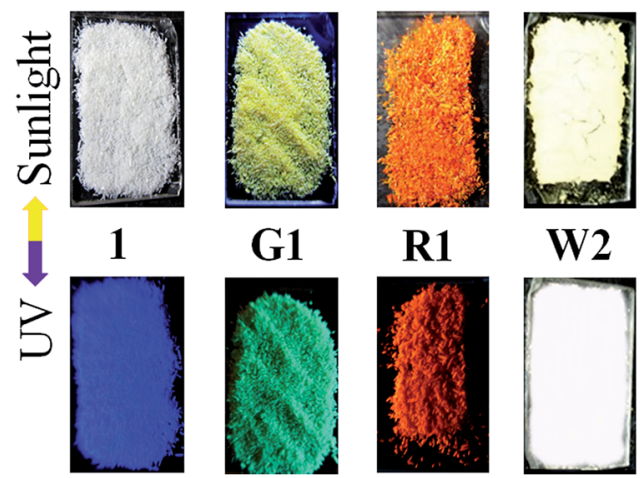

(c)

Fig. 2 Luminescent spectra (a) and CIE chromaticity coordinates (b) of $1 \supset\left([\mathrm{Ir}]^{+}+[\mathrm{Ru}]^{2+}\right)$ with different amounts of $[\mathrm{Ir}]^{+}$and $[\mathrm{Ru}]^{2+}\left(\lambda_{\mathrm{ex}}=365\right.$ nm); (W1: $1 \supset\left(0.88\right.$ wt\% $\left.[\mathrm{Ir}]^{+}+0.55 \mathrm{wt} \%[\mathrm{Ru}]^{2+}\right) ; \mathrm{W} 2: 1 \supset(0.28 \mathrm{wt} \%$ $\left.[\mathrm{lr}]^{+}+0.45 \mathrm{wt} \%[\mathrm{Ru}]^{2+}\right) ; \mathrm{W3}: 1 \supset\left(0.18 \mathrm{wt} \%[\mathrm{Ir}]^{+}+0.28 \mathrm{wt} \%[\mathrm{Ru}]^{2+}\right) ; \mathrm{W} 4:$ $1 \supset\left(0.18 w t \%[I r]^{+}+0.46 w t \%[R u]^{2+}\right) ; W 5: 1 \supset\left(0.13 w t \%[I r]^{+}+0.35 w t \%\right.$ $\left.[\mathrm{Ru}]^{2+}\right)$; W6: $1 \supset\left(0.065 \mathrm{wt} \%[\mathrm{Ir}]^{+}+0.46 \mathrm{wt} \%[\mathrm{Ru}]^{2+}\right) ; \mathrm{W} 7: 1 \supset(0.065 \mathrm{wt} \%$ $\left.\left.[\mathrm{lr}]^{+}+0.42 \mathrm{wt} \%[\mathrm{Ru}]^{2+}\right)\right)$. (c) Photographic images of 1 and its composites deposited on quartz slides under sunlight and under UV illumination at $365 \mathrm{~nm}$; (R1: $1 \supset 5.70 \mathrm{wt} \%[\mathrm{Ru}]^{2+}$; G1: $\left.1 \supset 5.90 \mathrm{wt} \%[\mid \mathrm{r}]^{+}\right)$.

concentrations in the solution. Among them, W2, namely $1 \supset\left(0.28 \mathrm{wt} \%[\mathrm{Ir}]^{+}+0.45 \mathrm{wt} \%[\mathrm{Ru}]^{2+}\right)$, displays broadband emission covering the whole visible spectral region with three main emissions peaking at 438, 472 and $580 \mathrm{~nm}$. Its corresponding CIE coordinate is $(0.33,0.34)$ which is very close to that of the pure WLE, $(0.33,0.33)$. Its calculated CCT value of $5604 \mathrm{~K}$ indicates that it is a positive white-light source. A comparison (Fig. 2C) of the colors of $\mathbf{1}$ and its composites under ambient conditions and upon UV light irradiation (at $365 \mathrm{~nm}$ ) further confirms the successful preparation of the composites.

\section{Sensing of VOSs by the WLE composite W2}

We then investigated the sensing behavior of W2 towards various VOSs. From the emission spectra of its suspensions in different VOSs (Fig. 3A), a unique combination of both $I_{\mathrm{MOF}} / I_{[\mathrm{Ir}]}{ }^{+}$ and $I_{\mathrm{MOF}} / I_{[\mathrm{Ru}]}{ }^{2+}$ are derived for each VOS. Such VOS-dependent ratiometric luminescence is caused by the changes of the MOFto-ELM energy transfer efficiencies and/or the energy allocation between $[\mathrm{Ir}]^{+}$and $[\mathrm{Ru}]^{2+}$ when different VOS molecules are included within the MOF channels/cages. ${ }^{13}$ Thus W2 is a selfcalibrating probe using the two ratios instead of using the single absolute emission-peak heights to identify VOSs. This sensing method is cheaper and more accurate and facile than the recently reported dual-readout sensing method that measures both single emission-peak height ratios and luminescence quantum yields using expensive and sophisticated equipment. $^{20}$ It is also different from a few reported dualratiometric luminescent sensing methods in which the duality refers to the capabilities of single ratiometric luminescent sensing to detect both $\mathrm{pH}$ and temperature. ${ }^{21}$

With the advantages mentioned above, W2 can unambiguously differentiate aromatic molecules with very similar structural motifs, such as $m$ - and $p$-xylene, benzene, toluene,

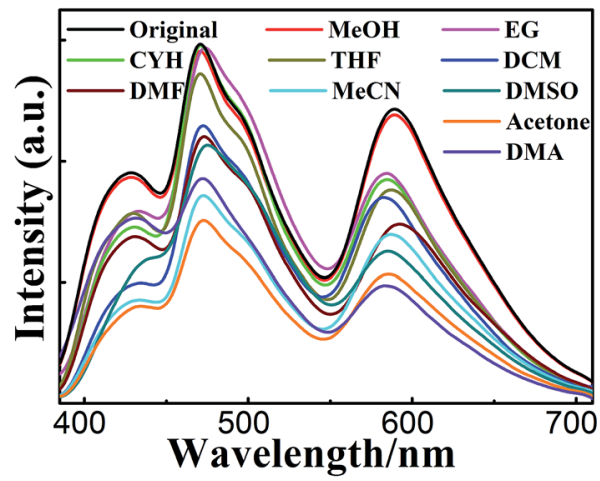

(a)

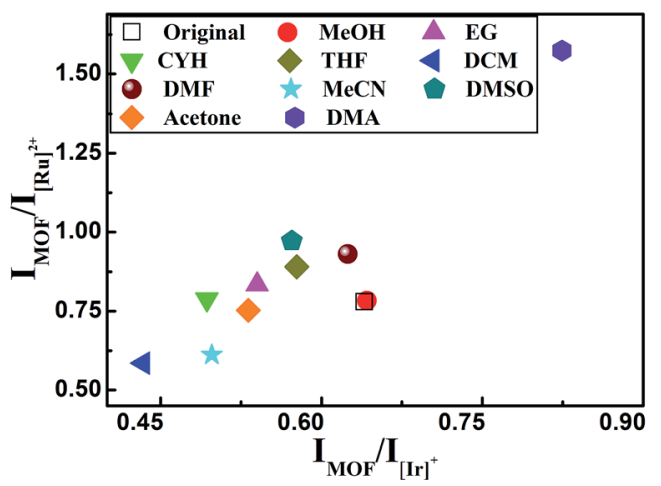

(b)

Fig. 3 (a-b) The emission spectra (a) and the corresponding 2D decoded map (b) of ten solvent molecules based on two emission intensity ratios: $I_{\mathrm{MOF}} / I_{[\mathrm{Ir}]}{ }^{+}$and $I_{\mathrm{MOF}} / I_{[\mathrm{Ru}]}{ }^{2+}$. 
bromobenzene (Br-benzene), fluorobenzene (F-benzene), and chlorobenzene (Cl-benzene) (Fig. 4A and B). Remarkably, under illumination at $365 \mathrm{~nm}$, W2 changed to blue or orange upon exposure to DMA or F-benzene, respectively, while being white or near-white upon exposure to other VOSs. Therefore, W2 is a selective and sensitive luminescent probe enabling the detection of DMA and F-benzene to be visible to the naked eye

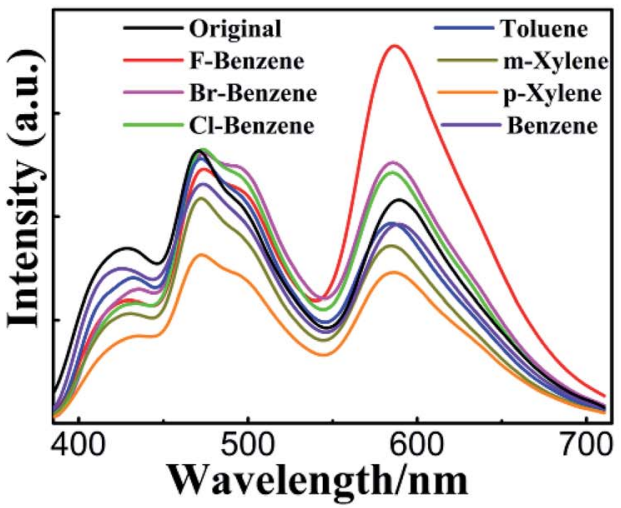

(a)

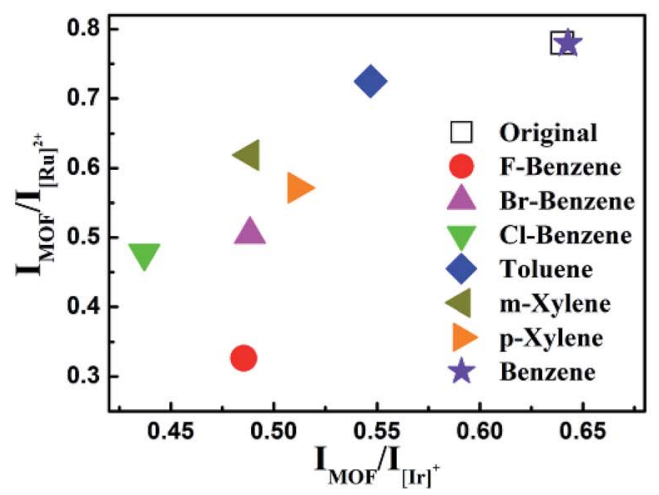

(b)

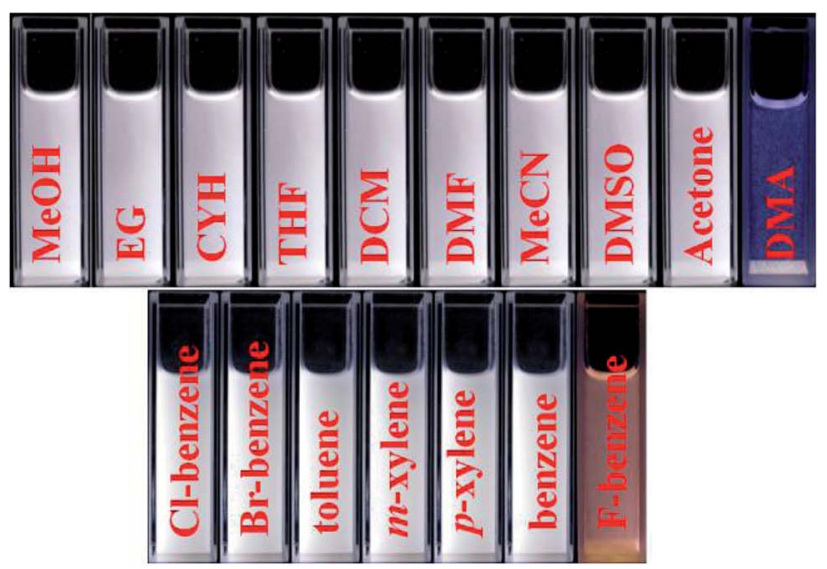

(c)

Fig. $4(a-b)$ The emission spectra (a) and the corresponding 2D decoded map (b) of seven structurally highly similar aromatic molecules based on two emission-intensity ratios: $I_{\mathrm{MOF}} / I_{[\mathrm{Irr}]}{ }^{+}$and $I_{\mathrm{MOF}} / /_{[\mathrm{Ru}]}{ }^{2+}$; (c) photographic images of the emulsions of W2 in different solvents under UV light irradiation at $365 \mathrm{~nm}$.
(Fig. 4C and S20†), possibly mainly due to the fact that DMA and F-benzene induce larger changes of the two ratios than other VOSs. It is worthy to note that so obvious color changes such as ours were observed in other luminescent sensing MOFs with strong host-analyte interactions ${ }^{\mathbf{1 2}}$ that are not required here.

\section{Sensing of NACs by the WLE composite W2}

We further explored the ability of $\mathbf{W} 2$ to probe NAC vapors by recording the luminescence spectra of its thin films before and immediately after being exposed to the equilibrated vapors of different NACs at $25{ }^{\circ} \mathrm{C}$ for $15 \mathrm{~min}$. The fifteen NACs under examination are nitrobenzene (NB), $m$-DNB, $o$-DNB, $p$-DNB, 1 nitrobromobenzene (1-NBB), 3-NBB, 4-NBB, 1-nitrotoluene (1NT), 3-NT, 4-NT, 1-nitronaphthalene (1-NP), 2-nitrophenol (2NPHEN), 4-nitrophenol (4-NPHEN), dinoseb, and 2,4,6-trinitrophenol (TNP). Among them, only the vapors of NB and $m$-DNB (Fig. 5A-C) can obviously quench the three main emissions (438 nm, $472 \mathrm{~nm}$, and $580 \mathrm{~nm}$ ) and the corresponding quenching efficiencies, calculated from the equation $\left[\left(I_{0}-I\right) / I_{0}\right]$ $\times 100 \%$ (where $I_{0}$ and $I$ are the initial luminescence intensity and the 15 min luminescence intensity upon exposure, respectively), are $15.4 \%, 26.9 \%$, and $20.1 \%$ for $\mathrm{NB}$, and $6.8 \%$, $12.4 \%$, and $9.8 \%$ for $m$-DNB (Fig. S21-S26†). The quenching could be due to the MOF-to-NAC electron transfers (Fig. S31 $\dagger$ ) and the higher vapor pressures of the two NACs. ${ }^{22}$ Detailed analyses of the CIE coordinates of each spectrum (Fig. 5C) during the quenching process indicate that the CIE coordinates keep changing during the process, possibly mainly due to their different quenching rates upon exposure to the same VOS vapour.

We further increased the sensing temperature to $40{ }^{\circ} \mathrm{C}$ and $60{ }^{\circ} \mathrm{C}$ to amplify the quenching-rate difference and the corresponding color changes during sensing. Compared to those obtained at $25{ }^{\circ} \mathrm{C}$ when $\mathbf{W} 2$ was exposed to $m$-DNB vapors for $15 \mathrm{~min}$, the quenching efficiencies of the three emissions at $60{ }^{\circ} \mathrm{C}$ were increased $\sim 10.4,5.9$ and 6.1 times to reach $77.5 \%$, $85.7 \%$, and $69.3 \%$, respectively (Fig. 5D-F, $15 \mathrm{~min}$ of exposure). Furthermore, during the first minute at $60{ }^{\circ} \mathrm{C}$, the $m$-DNB vapor induced the largest quenching-rate difference, and $I_{[\mathrm{Ir}]}{ }^{+}$was quenched much faster than $I_{[\mathrm{MOF}]}$ and $I_{[\mathrm{Ru}]}{ }^{2+}$ (Fig. 5D); therefore, W2 underwent a visible colour change under a standard UV lamp (365 nm) (Fig. 5G) to a distinctive dark orange colour (CIE coordinate: $0.39,0.35)$. After that, its color gradually returned but it did not reach the starting white color again. In contrast, $\mathrm{NB}$ and $o$-DNB induced a quenching effect at $40{ }^{\circ} \mathrm{C}$ and $60{ }^{\circ} \mathrm{C}$ to some extent, but the changes of the CIE coordinates were not significant enough to bring about visible luminescence color changes (Fig. S29†). The rapid and visible responses make W2 an unprecedentedly practical and selective probe for $m$-DNB, representing a significant step forward in reaching instantaneous, highly selective and sensitive detection of NAC vapors. In comparison, until now only a handful of MOFs have been used to sense non-NB NAC vapors, and during the sensing processes single emissions are quenched and turn dark while the changes generally are difficult to detect with the naked eye. ${ }^{\mathbf{4 , 5}}$ Moreover, many more MOF probes have been used to sense NACs in 


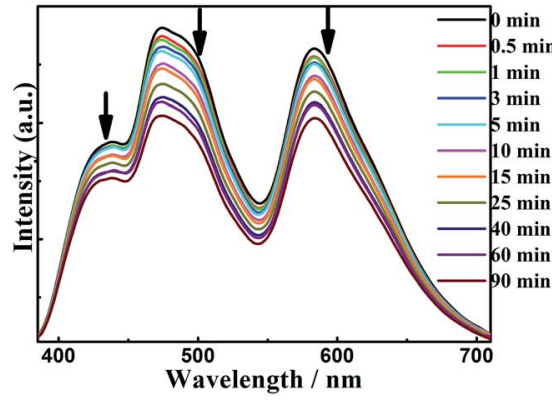

(a)

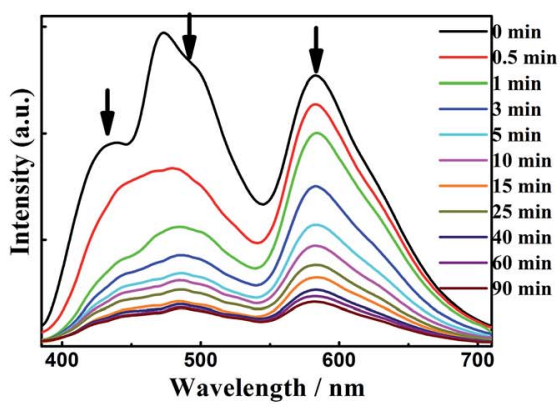

(d)

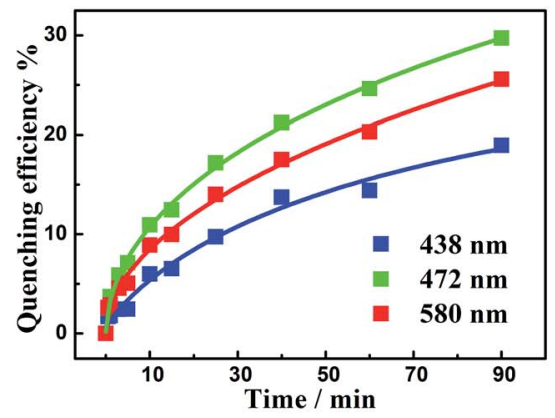

(b)

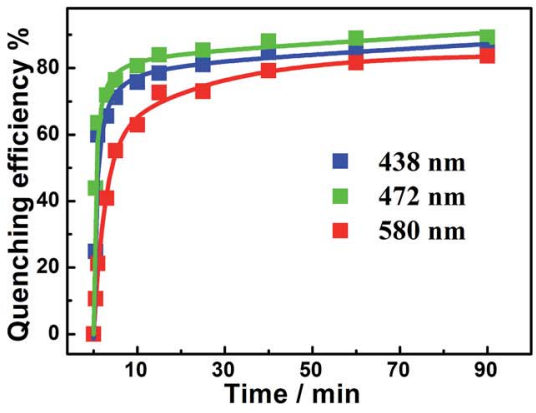

(e)

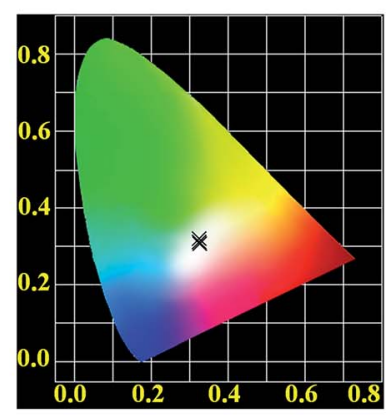

(c)

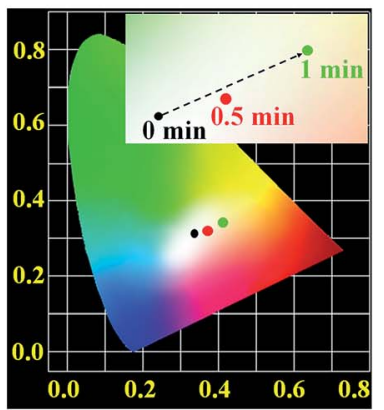

(f)

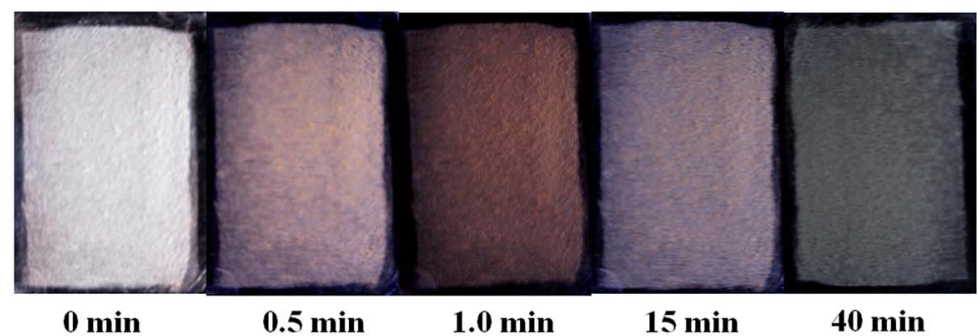

(g)

Fig. 5 (a-c) Time-dependent evolution of luminescence spectra (a), quenching efficiencies (b), and CIE coordinates (c) of W2 upon exposure to $m$-DNB vapour at $25^{\circ} \mathrm{C}$. (d-f) Time-dependent evolution of luminescence spectra (d), quenching efficiencies (e), CIE coordinates (f), and photographic images under UV illumination at $365 \mathrm{~nm}(\mathrm{~g})$ of W2 upon exposure to $\mathrm{m}$-DNB vapour at $60{ }^{\circ} \mathrm{C}$.

solutions with limited success in affording luminescence color changes that are visible to the naked eye. ${ }^{14,23}$ Unfortunately, after being quenched during the sensing experiments, the three emissions in $\mathbf{W} \mathbf{2}$ could only be partially regenerated after being washed with $\mathrm{MeOH}$ and dried, and thus the original ratiometric sensing behavior cannot be recovered.

To understand the mechanisms of their different quenching rates,we investigated the individual quenching behaviors of $\mathbf{1}$, $\left[\mathrm{Ru}(\mathrm{bpy})_{3}\right]\left(\mathrm{PF}_{6}\right)_{2}$ and $\left[\operatorname{Ir}\left(\mathrm{CF}_{3}-\mathrm{ppy}-\mathrm{F}_{2}\right)_{2}(\mathrm{bpy})\right] \mathrm{PF}_{6}$ by $m$-DNB at $60{ }^{\circ} \mathrm{C}$ (Fig. 6 and S27 $\dagger$ ). Indeed, $m$-DNB vapor can quench the emissions of 1 and $\left[\operatorname{Ir}\left(\mathrm{CF}_{3}-\text { ppy- } \mathrm{F}_{2}\right)_{2}(\mathrm{bpy})\right] \mathrm{PF}_{6}$ but not the emission of $\left[\mathrm{Ru}(\mathrm{bpy})_{3}\right]\left(\mathrm{PF}_{6}\right)_{2}$. The significantly changed MOF- $[\mathrm{Ru}]^{2+}$ interactions before and upon exposure to $m$-DNB vapor can explain why $m$-DNB vapor can quench the emission from the $[\mathrm{Ru}]^{2+}$ ELM in the composite. Before exposure to $m$-DNB vapor, the framework can amplify the ELM emissions in two ways. First, the spectral overlap between the emission from the framework and the absorption of $\left[\operatorname{Ir}\left(\mathrm{CF}_{3}-\mathrm{ppy}-\mathrm{F}_{2}\right)_{2}(\mathrm{bpy})\right] \mathrm{PF}_{6} /$
$\left[\mathrm{Ru}(\mathrm{bpy})_{3}\right]\left(\mathrm{PF}_{6}\right)_{2}$ (Fig. S19†) can enhance the ELM emissions. Second, the framework provides an excellent environment that can restrain the mobile movement of the ELMs and thus significantly suppress the aggregation-induced quenching. ${ }^{18}$ In contrast, in the physical mixture of the three compounds in the same weight ratio, the emissions from $\left[\mathrm{Ru}(\mathrm{bpy})_{3}\right]\left(\mathrm{PF}_{6}\right)_{2}$ and $\left[\operatorname{Ir}\left(\mathrm{CF}_{3}-\mathrm{ppy}-\mathrm{F}_{2}\right)_{2}(\mathrm{bpy})\right] \mathrm{PF}_{6}$ slightly alter the emission from the framework in the range of $450-700 \mathrm{~nm}$ (Fig. S32 $\dagger$ ). Upon exposure to $m$-DNB vapor, the photo-induced electron transfers from the conduction band (CB) of the electron-rich framework to the lower LUMO orbitals of the electron-deficient $m$-DNB rather than to the ground state with relaxation, which leads to the quenching of the emission from the framework. ${ }^{22}$ Such quenching leads to a significantly reduced MOF-to-[Ru $]^{2+}$ energy transfer and the subsequent quenching of the emission from $[\mathrm{Ru}]^{2+}$. This quenching route also applies in the case of $[\mathrm{Ir}]^{+}$that is further directly quenched by $m$-DNB. As a result, the three components have different quenching rates. Investigations 


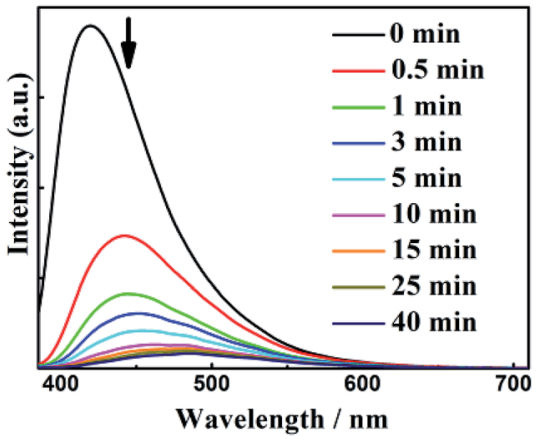

(a)

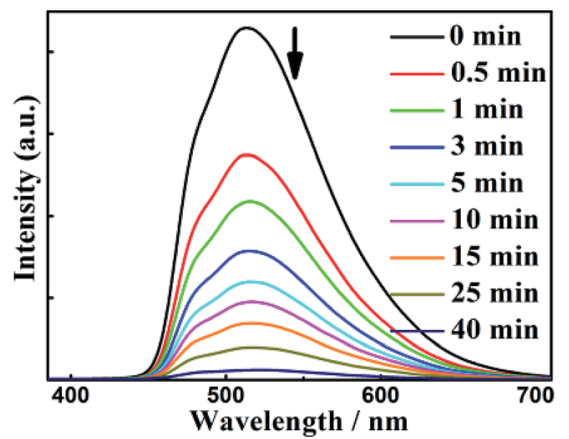

(b)

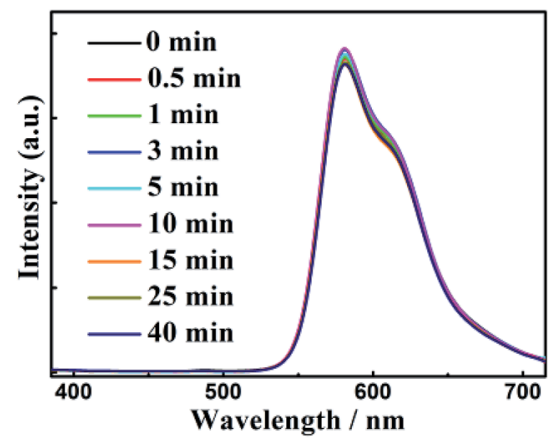

(c)

Fig. 6 Time-dependent evolution of the luminescence spectra of 1 (a), $\left[\operatorname{Ir}\left(\mathrm{CF}_{3}-\mathrm{ppy}-\mathrm{F}_{2}\right)_{2}(\mathrm{bpy})\right] P F_{6}(\mathrm{~b})$, and $\left[\mathrm{Ru}(\mathrm{bpy})_{3}\right]\left(\mathrm{PF}_{6}\right)_{2}$ (c) upon exposure to $m$-DNB vapour at $60^{\circ} \mathrm{C}$.

toward further understanding of the underlying mechanisms are ongoing.

Interestingly, the luminescent sensing of NAC vapors at $60{ }^{\circ} \mathrm{C}$ can be further improved by recording the time-dependent evolution of the two ratios (Fig. 7). For the twelve NACs without quenching inducing behaviors, all their data points $\left(I_{\mathrm{MOF}} / I_{[\mathrm{Ir}]}{ }^{+}\right.$: $\left.0.64-0.68 ; I_{\mathrm{MOF}} / I_{[\mathrm{Ru}]}^{2+}: 0.73-0.77\right)$ during the sensing processes are very close to the original value of $(0.650,0.777)$ and are densely located in a small region, possibly due to random and/ or systematic errors. In contrast, although the data points of NB, $m$-DNB, and $o$-DNB before and during the initial sensing are located in the same region, they move into totally different regions in the subsequent sensing (Fig. 7A). When time is added as the third dimension, a novel $3 \mathrm{D}$ code recognition can be mapped out to further distinguish them (Fig. 7B). Here, W2

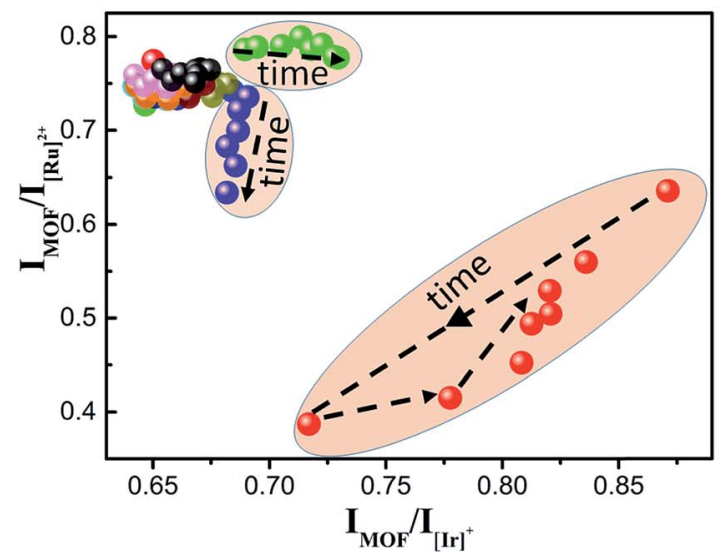

(a)

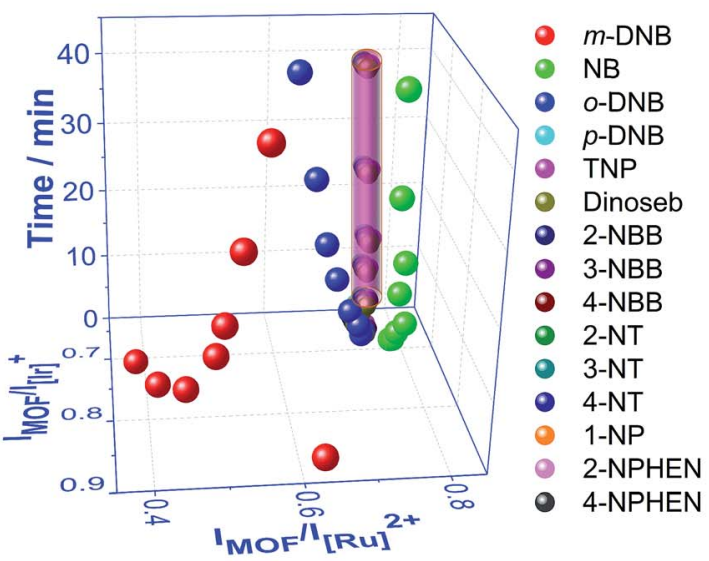

(b)

Fig. 7 (a) The time-dependent 2D ratiometric sensing of fifteen NAC vapours by $\mathrm{W} 2$ at $60^{\circ} \mathrm{C}$, and (b) the derived $3 \mathrm{D}$ ratiometric sensing of the NAC vapours when time is added as the third dimension (note: the overlapped data points from the twelve NAC vapors without quenching effects are combined to form a column).

identifies a series of analytes with similar structures and luminescence changes that generally cannot be differentiated by probes based on single or dual emissions, providing a new direction for luminescent sensing.

\section{Conclusions}

In summary, we have successfully developed a novel WLE MOFbased composite as the first multidimensional ratiometric luminescent probe. It is facilely obtained by incorporating two luminescent complex cations as ELMs into an anionic, porous and luminescent MOF. Upon exposure to selective VOSs or NAC vapors, the two MOF-to-ELM ratios of emission-peak heights undergo analyte-dependent changes, leading to drastic luminescence color changes and making W2 a highly sensitive and selective luminescent probe. The novel sensing upgrades current state-of-the-art 1D ratiometric luminescent sensing into 2D and 3D versions, highlighting a new direction for achieving more facile and efficient luminescent sensing. Furthermore, the post-synthetic method described here can be employed to 
develop more multi-chromatic (e.g., tetrachromatic) probes using numerous available and suitable porous materials (including MOF hosts) and ELM species to achieve even higher dimensional code recognition. In short, this work opens up fresh opportunities to develop new composites for luminescent sensing and related applications.

\section{Conflicts of interest}

There are no conflicts to declare.

\section{Acknowledgements}

This material is based upon work supported by the National Natural Science Foundation of China (21071025, 21471024), the instrumental analysis fund of DUT, and the Fundamental Research Funds for the Central Universities (DUT15ZD118 and DUT16ZD205). BSRF (Beijing Synchrotron Radiation Facility) is also acknowledged for the crystal structure determination using synchrotron radiation X-ray diffraction analysis.

\section{References}

1 Chemiluminescence in Analytical Chemistry, ed. A. M. GarciaCampana and W. R. G. Baeyens, Marcel Dekker, New York, 2001.

2 Y. Lyu and K. Pu, Adv. Sci., 2017, 4, 1600481.

3 Y. Yang, Q. Zhang, W. Feng and F. Li, Chem. Rev., 2013, 113, 192; N. Ahmad, H. A. Younus, A. H. Chughtaiabd and F. Verpoort, Chem. Soc. Rev., 2015, 44, 9.

4 A. Karmakar, P. Samanta, A. V. Desai and S. K. Ghosh, Acc. Chem. Res., 2017, 50, 2457; W. P. Lustig, S. Mukherjee, N. D. Rudd, A. V. Desai, J. Li and S. K. Ghosh, Chem. Soc. Rev., 2017, 46, 3243; B. Yan, Acc. Chem. Res., 2017, 50, 2789.

5 X. Zhang, W. Wang, Z. Hua, G. Wang and K. Uvdal, Coord. Chem. Rev., 2015, 284, 206; Z. C. Hu, B. J. Deibert and J. Li, Chem. Soc. Rev., 2014, 43, 5815; Y. Cui, Y. Yue, G. Qian and B. Chen, Chem. Rev., 2012, 112, 1126.

6 A. Schoedel, M. Li, D. Li, M. O'Keeffe and O. M. Yaghi, Chem. Rev., 2016, 116, 12466; Y. Bai, Y. B. Dou, L. H. Xie, W. Rutledge, J. R. Li and H. C. Zhou, Chem. Soc. Rev., 2016, 45, 2327; J. J. Perry, J. A. Perman and M. J. Zaworotko, Chem. Soc. Rev., 2009, 38, 1400; Q.-L. Zhu and Q. Xu, Chem. Soc. Rev., 2014, 43, 5468.

7 J.-J. Zhang, H.-J. Zhou and A. Lachgar, Angew. Chem., Int. Ed., 2007, 46, 4995; J.-J. Zhang, L. Wojtas, R. W. Larsen, M. Eddaoudi and M. J. Zaworotko, J. Am. Chem. Soc., 2009, 131, 17040; J. Lu and R. Cao, Angew. Chem., Int. Ed., 2016, 55, 9474; M. A. Nasalevich, R. Becker, E. V. RamosFernandez, S. Castellanos, S. L. Veber, M. V. Fedin, F. Kapteijn, J. N. H. Reek, J. I. van der Vlugt and J. Gascon, Energy Environ. Sci., 2015, 8, 364.

8 X. Lin, Y. Hong, C. Zhang, R. Huang, C. Wang and W. Lin, Chem. Commun., 2015, 51, 16996.

9 S.-Y. Zhang, W. Shi, P. Cheng and M. J. Zaworotko, J. Am. Chem. Soc., 2015, 137, 12203; P. Y. Wu, J. Wang, C. He,
X. L. Zhang, Y. T. Wang, T. Liu and C. Y. Duan, Adv. Funct. Mater., 2012, 22, 1698; P. Y. Wu, J. Wang, Y. M. Li, C. He, Z. Xie and C. Y. Duan, Adv. Funct. Mater., 2011, 21, 2788.

10 M. S. Wang, S. P. Guo, Y. Li, L. Z. Cai, J. P. Zou, G. Xu, W. W. Zhou, F. K. Zheng and G. C. Guo, J. Am. Chem. Soc., 2009, 131, 13572; M. D. Allendorf, C. A. Bauer, R. K. Bhaktaa and R. J. T. Houk, Chem. Soc. Rev., 2009, 38, 1330.

11 J.-W. Ye, J.-M. Lin, Z.-W. Mo, C.-T. He, H.-L. Zhou, J.-P. Zhang and X.-M. Chen, Inorg. Chem., 2017, 56, 4238.

12 R. Haldar, R. Matsuda, S. Kitagawa, S. J. George and T. K. Maji, Angew. Chem., Int. Ed., 2014, 53, 11772; R. Haldar, K. Prasad, P. K. Samanta, S. Pati and T. K. Maji, Cryst. Growth Des., 2016, 16, 82.

13 M. J. Dong, M. Zhao, S. Ou, C. Zou and C. D. Wu, Angew. Chem., Int. Ed., 2014, 53, 1575; S. N. Zhao, X. Z. Song, M. Zhu, X. Meng, L. L. Wu, J. Feng, S. Y. Song and H. J. Zhang, Chem.-Eur. J., 2015, 21, 9748; Y. Cui, R. Song, J. Yu, M. Liu, Z. Wang, C. Wu, Y. Yang, Z. Wang, B. Chen and G. Qian, Adv. Mater., 2015, 27, 1420.

14 D. M. Chen, N. N. Zhang, C. S. Liu and M. Du, ACS Appl. Mater. Interfaces, 2017, 9, 24671; X. L. Hu, C. Qin, X. L. Wang, K. Z. Shao and Z. M. Su, Chem. Commun., 2015, 51, 17521.

15 W. Huang, F. Pan, Y. Liu, S. Huang, Y. Li, J. Yong, Y. Li, A. M. Kirillov and D. Wu, Inorg. Chem., 2017, 56, 6362; X. Zhang, Q. Hu, T. Xia, J. Zhang, Y. Yang, Y. Cui, B. Chen and G. Qian, ACS Appl. Mater. Interfaces, 2016, 8, 32259.

16 Topos Main Page, http://www.topos.ssu.samara.ru.

17 A. L. Spek, PLATON, Multipurpose Crystallographic Tool, Utrecht University, Utrecht, The Netherlands, 2008.

18 C. Y. Sun, X. L. Wang, X. Zhang, C. Qin, P. Li, Z. M. Su, D. X. Zhu, G. G. Shan, K. Z. Shao, H. Wu and J. Li, Nat. Commun., 2013, 4, 2717; Y. J. Cui, T. Song, J. C. Yu, Y. Yang, Z. Y. Wang and G. D. Qian, Adv. Funct. Mater., 2015, 25, 4796; Y.-H. Wen, T.-L. Sheng, X.-Q. Zhu, C. Zhuo, S.-D. Su, H.-R. Li, S.-M. Hu, Q.-L. Zhu and X.-T. Wu, Adv. Mater., 2017, 29, 1700778; W. Xie, W.-W. He, D.-Y. Du, S.-L. Li, J.-S. Qin, Z.-M. Su, C.-Y. Sun and Y.-Q. Lan, Chem. Commun., 2016, 52, 3288.

19 T. Fleetham, G. Li and J. Li, Adv. Mater., 2017, 29, 1601861; R. D. Hancock, Chem. Soc. Rev., 2013, 42, 1500; M. L. Saha, X. Yan and P. J. Stang, Acc. Chem. Res., 2016, 49, 2527.

20 Y. Zhou and B. Yan, Chem. Commun., 2016, 52, 2265.

21 X. Wan and S. Liu, J. Mater. Chem., 2011, 21, 10321; A. E. Thorarinsdottir, K. Du, J. H. P. Collins and T. D. Harris, J. Am. Chem. Soc., 2017, 139, 15836; X. X. Hu, Y. Q. Wang, H. Y. Liu, J. Wang, Y. N. Tan, F. B. Wang, Q. Yuan and W. H. Tan, Chem. Sci., 2017, 8, 466; X. X. Hu, T. Wei, J. Wang, Z.-E. Liu, X. Y. Li, B. H. Zhang, Z. H. Li, L. L. Li and Q. Yuan, Anal. Chem., 2014, 86, 10484.

22 S. Pramanik, C. Zheng, X. Zhang, T. J. Emge and J. Li, J. Am. Chem. Soc., 2011, 133, 4153; L. Di, J.-J. Zhang, S.-Q. Liu, J. Ni, H. Zhou and Y.-J. Sun, Cryst. Growth Des., 2016, 16, 4539; Y. Dai, H. Zhou, X.-D. Song, J.-J. Zhang, C. Hao, L. Di, 
Y.-X. Wang, J. Ni and H.-L. Wang, CrystEngComm, 2017, 19, 2786.

23 Y. Zhang, B. Li, H. Ma, L. Zhang and W. Zhang, J. Mater. Chem. C, 2017, 5, 4661; X. Qi, Y. Jin, N. Li, Z. Wang,
K. Wang and Q. Zhang, Chem. Commun., 2017, 53, 10318; C. Wang, L. Tian, W. Zhu, S. Wang, P. Wang, Y. Liang, W. Zhang, H. Zhao and G. Li, ACS Appl. Mater. Interfaces, 2017, 9, 20076. 